Some of the peculiarities of the Wilder system are then briefly discussed, attention being called to its disregard of the ordinary principles of language formation as exemplified by : 1st. The mutilation of words, as by using 'alinjection,' for injection with alcohol ; chippocamp, for hippocampus major, etc. 2 d. The substitution of monomial terms ('mononyms,' Wilder) for those sanctioned by long usage and historic precedent. In recent publications we are asked, for example, to say ' restis,' for restiform body; 'praecribrum,' for anterior perforated space; and 'quadrigeminum,' for corpora quadrigemina. In this matter the majority of anatomists will probably agree with Professor His that "the contraction of several words into one may under certain circumstances be an improvement, but as the conciseness of a telegram may lead to its obscurity, so terms used in this way may, from their very brevity, demand a special explanation for their comprehension."* Dr. Dwight cites, with approval, the writer in Nature who styles this system a scientific Volapük. Dr. Wilder himself recognizes the necessity for furnishing a vocabulary for his peculiar tongue, as is done with the artificial language just cited, for his longer essays are accompanied by a chapter of definitions, and his shorter ones have numerous parenthetic interpolations for explaining the meaning of his terms.

The degrading influence that such inartistic curtailments must have upon ordinary literary style is pointed out by Dr. Dwight. We notice in a recent publication from Dr. Wilder's pen that 'anatomic teachers' are mentioned, by which grisly term he apparently means teachers of anatomy.

Dr. Dwight suggests that some of the oddities of this system have, doubtless, arisen because of the peculiar isolation of Dr. Wilder from those who are using human anatomy practically and who, therefore, feel the necessity of preserving unbroken the traditions of anatomical speech. Medicine and surgery have never been taught at Cornell University, and Professor Wilder's chair is not that of human anatomy.

The general verdict of foreign anatomists is

* Die Anatomische Nomenclatur, p. 7 . strongly against these innovations, and is well voiced by the following temperate and wise rebuke administered by the veteran Kölliker, who was Chairman of the Committee on Nomenclature of the Anatomische Gesellschaft:

"I regard the anatomical nomenclature that has emanated from America in recent years as a complete failure, and so inappropriate that it is impossible for me to read articles based thereon. One can hardly ask a scholar who has received a regular training to accept quietly the many barbarisms of this nomenclature, such as metatela, metaplexus, auliplexus, diaplexus, ectocinerea, cephalad, caudad, dorsad, cephalo-dorsad, ventro-caudad, dorso-caudad, hemi-cerebrum, etc., and to turn back and find out the meaning of a great number of other terms, such as terma, proton, pero, prosoterma, diaterma, supraplexus, aula, alba, crista, diacoele, mesocoele, etc. As the oldest German anatomist, I may, perhaps, be permitted to advise my American colleagues not to proceed farther upon this path lest it might happen that, in the course of a few years, the anatomists on this and on that side of the water no longer understand each other and all scientific interchange of ideas become impossible." $*$

Dr. Dwight protests against the designation 'American' as applied to the Wilder system, and closes his too brief article as follows:

"As regards the future it may be that an unexpected prophecy may be deduced from its likeness to Volapük. That pseudo-speech has fallen, apparently never to rise again. Whether the Wilder system as a whole will outlive the loss of the great influence and enthusiasm of its author, which must naturally occur in the course of human events, is very doubtful; it is certain, however, that whatever good there is in it will survive beyond that day which we hope may still be far distant."

\section{Frank BAKer.}

\section{A Description of Minerals of Commercial Value.} By D. M. Barringer. New York, Wiley \& Sons. 1897. First edition. Pp. 168.

Barringer's 'Minerals of Commercial Value' is a small volume bound in flexible cloth issued

* Kölliker, A. 'Handbuch der Gewebelehre des Menschen.' 6te Aufl. Band II., p. 814. 
for the use of miners, prospectors and business men. From its preface we learn that "the work is intended merely as a book of reference to be used by the practising miner or man of business, for whom especially it is intended, as well as by the geologist, metallurgist or mineralogist in so far as it may serve their purposes. *** The original intention of the author was to give, in as simple and concise a form as possible, a description of the nature of only the more important of those mineral substances, more frequently referred to as ores or compounds, which possess commercial value, indicating at the same time means by which they could be identified, and referring very briefly to some of the principal economic uses to which they are put. Upon reflection, however, it seemed advisable* *to insert also a description of a few other minerals which are very frequently met with as common veinstones or as rock constituents, although they may possess in themselves no commercial value." In short, the book is a work on determinative mineralogy in which, however, only the most important compounds are discussed. There is nothing noteworthy in the treatment of its subject-matter, unless it be the arrangement of the minerals according to their metallic constituent. Whether this manner of arrangement is as good as one based on hardness, density or some other physical property is at least doubtful. Indeed, it is prob. able the book throughout is too technical for miners, prospectors and business men, though it may easily be of assistance to metallurgists and geologists, more because of its convenient form than because of anything of especial value in its contents.

The first part of the volume contains a list of atomic weights, statements of the characteristics of the crystal systems, the scale of hardness and brief descriptions of the most important blow-pipe reactions and wet tests for the different chemical elements.

The second part is made up exclusively of tables. The minerals of each metal are listed alphabetically and opposite each is given its chemical composition, a statement of its general character and its occurrence, a description of its behavior toward reagents, its color, lustre, etc., and, finally, an account of its uses. In three appendices following the lists of minerals is a condensed form of Brush's classification of minerals according to lustre and fusibility, a list of simple tests for the most important chemical elements and a brief description of the simpler processes of assaying.

The book is carefully compiled and is well printed. It is accurate and therefore trustworthy. Although, as has already been stated, it contains no novel features, it will serve as a convenient companion, because of its handy size, to any one capable of using it. It is the most compact determinative mineralogy in the market.

\section{Colby UNIVERsity.}

W. S. BAYLEY.

SCIENTIFIC JOURNALS.

The Journal of Geology for February-March, 1898 (Vol. VI., No. 2), contains the following papers: 'Brazilian Evidences on the Genesis of the Diamond,' by Orville A. Derby. The author endeavors to draw a parallel between the geology of the South African Diamonds and of those of Brazil. Three Brazilian localities in Minas Geraes are selected, viz., San Joâo da Chapada, Grâo Mogol and Agua Suja. At the first it is uncertain whether the diamonds are derived from phyllites or from contact zones in the phyllites next intrusions of pegmatites, or from the pegmatites. In the second locality they seem to be allothigenic minerals in metamorphosed clastics. At the third place there are basic intruded rocks, more or less analogous to those at Kimberley, but it is still an open question whether the diamonds have been derived from them or from the neighboring schists. Excessive weathering and the present abandoned condition of the Brazilian mines mask the evidence. 'The Glaciation of North Central Canada,' J. P. Tyrrell. The author describes the three successive glaciers of this portion of Canada, viz: 1st, the Cordilleran, that spread from the Cordilleras eastward and then retreated; $2 d$, the Keewatin, that originated northwest of Hudson Bay and spread north, west, south, and to some degree east, and withdrew ; $3 \mathrm{~d}$, the Labradorean, that began in central Labrador, spread in all directions, but especially southward, and on the northwest lapped 